\title{
CHARACTERISTICS OF ACUTE TOXICITY DYNAMICS OF SELECTED TOXICANTS ON AQUATIC CRUSTACEANS
}

\author{
CHARAKTERYSTYKA DYNAMIKI TOKSYCZNOŚCI OSTREJ \\ WYBRANYCH TOKSYKANTÓW NA WODNYCH SKORUPIAKACH
}

\begin{abstract}
Determining the value of a half-effective or half-life concentration or dose of toxicant is the main purpose of acute toxicity studies, and this is also the most commonly used value in the toxicity characteristics of substances. By conducting tests that meet the criteria and requirements for the determination of acute toxicity, due to the use of appropriate mathematical tools and concentrations resulting in complete lethal effects in the studied groups, considerably more important values can be achieved, which give a possibility for the analysis of the entire process's dynamics, as well as determining the threshold values of the effect time and toxicant concentration. This was the purpose of our research, in which the research species were Daphnia magna and Cypris pubera. The effect of the conducted research allowed to determine and compare the two toxicants: ammonium and copper(II) ions by it's: concentration limit values $\left(C_{t h}\right)$, internal toxicity of the receptor-ligand complex $(\alpha)$, apparent, constant disintegration of this complex $\left(K_{a p p}\right)$ and different time values of the effect $\left(T_{t}, T_{i n}, M L T\right)$, which, along with concentration, is equally important determinant of the development of a toxic effect.
\end{abstract}

Keywords: acute toxicity, copper and ammonium ions, threshold concentration, Daphnia magna, Cypris pubera

\section{Introduction}

The growing pollution of waters along with the lack of fresh water is a global environmental problem [1]. In water reservoirs contaminated by substances of anthropogenic origin, increasing toxicity for most aquatic organisms is already manifested even at small concentrations of toxicants. The highest risk to the aquatic environment is caused by heavy metals, such as copper, nickel, zinc or cobalt [2-5]. These metals are able to interfere with the integrity of physiological and biochemical processes and lead to significant changes in metabolic reactions in aquatic organisms [6, 7]. In micro-quantities, these metals are necessary for living organisms, but their excess lead to undesirable effects. Nitrogen-containing compounds are, next to heavy metals, a big threat to hydrobionts and the general condition of water reservoirs, because they significantly degrade composition of gases dissolved in water and hydrochemical composition of water itself, and tend to accumulate in the form of nitrites and nitrates in hydrobionts [8]. Hydrobionts react

\footnotetext{
${ }^{1}$ Institute of Biotechnology and Molecular Biology, University of Opole, ul. kard. B. Kominka 6a, 45-032 Opole, Poland, phone +48774016050

*Corresponding author: golos@uni.opole.pl
} 
differently to toxic substances, which is why observations of different species in laboratory conditions allow to assess the effects caused both by natural and anthropogenic factors in the natural ecosystem and to predict the direction of changes occurring in their bodies. The main goal for most of toxicity studies is to predict the influence of toxicant on biotic elements of environment [9], and so it was also in this case. Extrapolation of laboratory results to different species and environmental conditions is bound with greater uncertainty, therefore, toxicity models which include more parameters, than only a concentration of the toxicant, are more valuable and useful. Still, chemicals considered as an environmental pollutants, when present all together in water, may cause higher risk due to additive effects or lower due to competition for bounding to biological ligands [10]. One of most suitable, water species for complex toxicity studies is Daphnia magna which is favorable laboratory organism worldwide [11], due to their sensitiveness, live cycle, ease of maintenance culture. Toxicity of different metals to this species is well known and has been already compared, but the effect of establishing relationships between toxicity of this pollutants are not yet satisfactory [12]. Copper ions toxicity was compared between different species of Daphnia, giving significant differences among them [13], but comparing the same toxicant using other species of water crustaceans is another step forward in understanding and predicting the toxic effects.

The aim of this work was to study and compare parameters of the dynamics of the toxic effect of ammonium and copper(II) ions on water crustaceans, which are toxicants disrupting and limiting effectiveness of water ecosystems.

\section{Materials and methods}

\section{Substances}

The anhydrous salt of ammonium chloride and copper sulfate were used to study the development of the toxic effect. These substances were chosen due to the commonness of the environmental pollutants with copper and nitrogen compounds. The range of concentrations of ammonium chloride used ranged from 0.3125 to $5 \mathrm{~g} / \mathrm{dm}^{3}$, copper sulfate from 0.00625 to $0.1 \mathrm{mg} / \mathrm{dm}^{3}$. For purposes of studies and due to specific, mathematical models used to determine the toxic effects we used higher, than environmental, concentrations of toxicants.

\section{Studied species}

Two species of aquatic crustaceans were used for the study: genetically homogeneous, synchronized Great Daphnia (Daphnia magna) cultures and ostracods (Cypris pubera). Only adult, fully grown daphnids were used in studies due to differences of toxicity of ammonium and copper between adults and immature specimens in Daphnia magna and other water invertebrates according to OECD guidelines [14].

\section{Exposition on toxicant and conditions}

Each probe of tested animals contained about 50 to 150 individuals which were placed in a $0.5 \mathrm{dm}^{3}$ vessel. The study was made according to acute toxicity tests guidelines and procedures by OCED [14]. The research was carried out using a static model - the concentration range of the tested toxicants was constant over time and from the concentration zone causing death of the entire group of specimens. Water has not been 
changed during exposure to the toxicant. The exposure time dependent on the death of the last individual from a given research group.

\section{Calculation of toxicodynamics parameters and statistics}

The probability of the lethal effect $(P)$ was counted as the ratio of the number of dead individuals at a given time $(n)$ to the total number of subjects tested $(N): P=n / N$. The probability of survival $(Q)$ was calculated as $(1-P)$. The mathematical apparatus of previously published models was used to calculate the data, which allows to determine the initial $\left(T_{i n}\right)$, terminal time $\left(T_{t}\right)$, mean survival time $(M L T)$, the "intrinsic toxicity" of complex "receptor-ligand (toxicant)" $(\alpha)$, and the apparent decay of constant of these complexes $\left(K_{a p p}\right)$ [10-12]. The statistical significance of the differences was calculated using the Student's $t$ test $(t)$ at the significance level of $p \leq 0.05$ and ANOVA.

\section{Results}

\section{Dynamics of toxic effects in Daphnia magna caused by ammonium ions}

For this species we used concentrations of 0.3125 to $5 \mathrm{~g} / \mathrm{dm}^{3}$ of ammonium chloride during toxicity studies. The exposure time for the lowest concentration used was 6 hours and 28 minutes. Values of $T_{\text {in }}$ of the toxic effect for the whole range of concentrations were similar, except for the highest concentration. However, differences were recorded in $T_{t}$, where the value for the smallest concentration differ from every other. The values of the average time of survival increased in parallel with the concentration of the toxicant (Fig. 1).

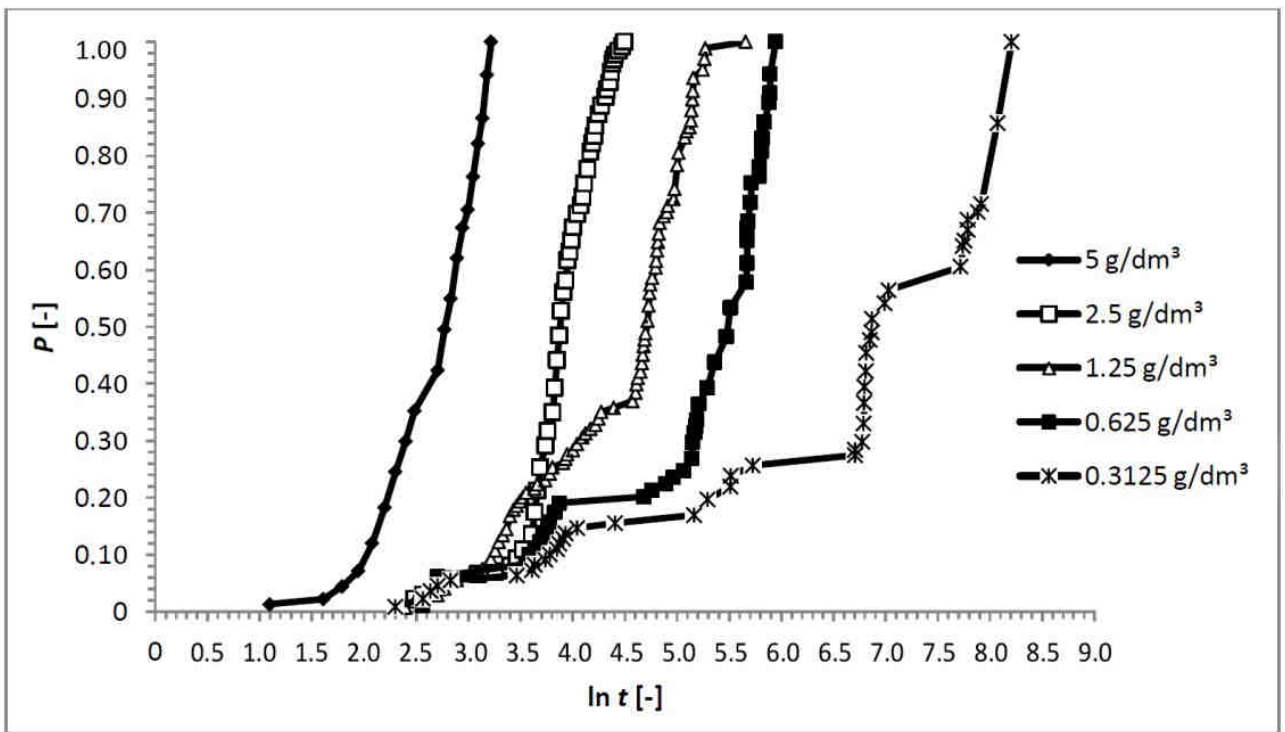

Fig. 1. The dependence of the probability of a lethal toxic effect $(P)$ on the logarithm of time for Daphnia magna organisms at various concentrations of ammonium chloride 
More precise analysis of the dynamics of the toxic effects of toxicants is based on the fact that in the coordinates of $(\ln Q)$ and $(t)$ the process going without acceleration and deceleration (constant probability of effect realization) takes the form of a straight line. If in the process of the toxic effect the organism's resistance to toxicants is increased, the research data in the coordinates indicated are arranged in a concave line - the process is slowed down. If the toxicant accumulates in the body or resistance to its effects decreases, then the research data are arranged in a convex line - the process proceeds with acceleration.

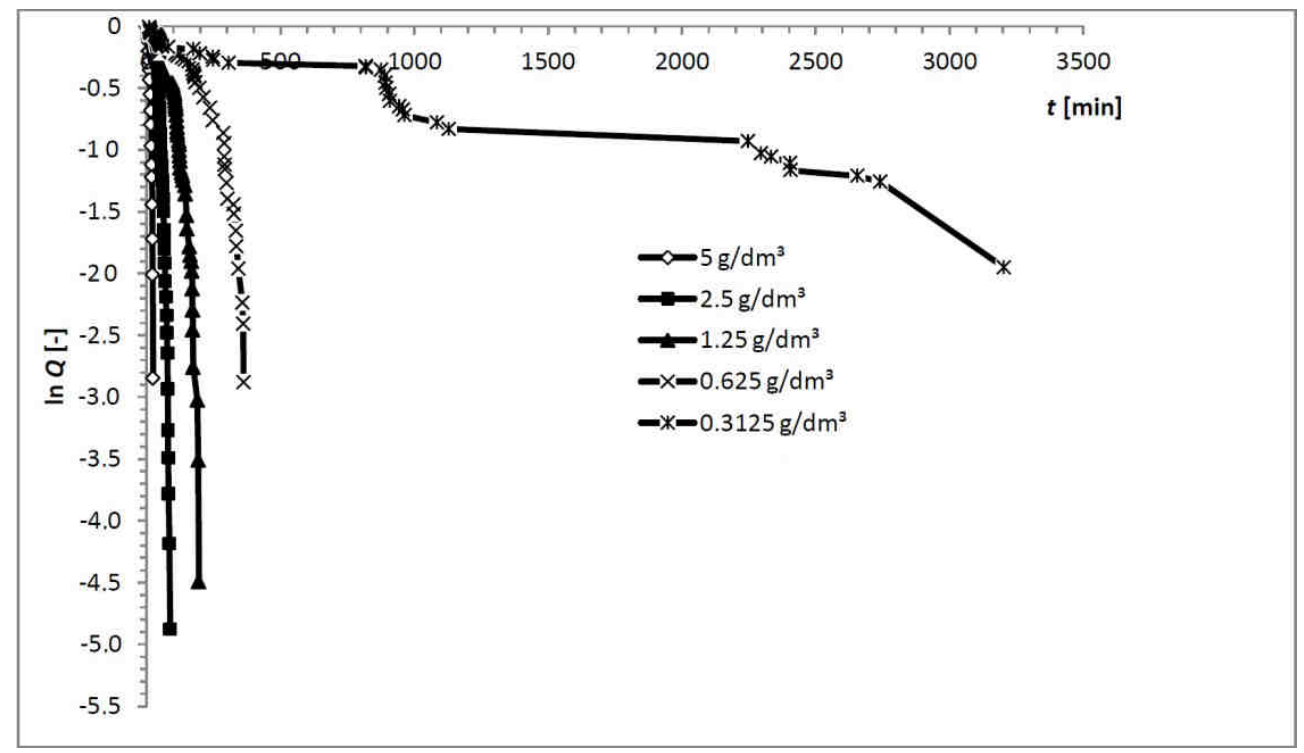

Fig. 2. The dynamics of survival ( $\ln Q$ ) of Daphnia magna under the exposure to various concentrations of ammonium chloride

The dynamics of survival (Fig. 2) shows that the lethal effect of individuals in all concentrations, except for the lowest one, occurs quickly and almost simultaneously in a relatively short time from the beginning of exposure. The lowest concentration of ammonium chloride takes the form of a straight line, what proves the exponential dependence. The discrepancy between the highest and lowest concentrations suggests the existence of two types of effects - acute and subacute. In order to confirm or reject this hypothesis, the method of computer simulation of research data in coordinates $\left(P, \ln \left(t C^{n}\right)\right)$ was used to estimate the size of the exponent of function $(n)$. This way of presenting experimental data allow to recognize what follows: if the effect in the range of tested concentrations is only one, the "effect - time" curves obtained at various concentrations of the toxic compound are not concentration-dependent - so they fit all together. The simulation showed the existence of only one type of lethal effect - this is an acute effect. The results of development of the toxic effect of ammonium chloride in Daphnia magna are presented in Table 1. 
Basic parameters of the time of toxic effect for Daphnia magna in the presence of various concentrations of ammonium ions

\begin{tabular}{|c|c|c|c|}
\hline $\boldsymbol{C}\left[\mathbf{g} / \mathbf{d m}^{3}\right]$ & $\boldsymbol{T}_{\text {in }}[\mathbf{m i n}]$ & $\boldsymbol{T}_{t}[\mathbf{m i n}]$ & $\boldsymbol{M L T}[\mathbf{m i n}]$ \\
\hline 5 & 3 & 25 & $15.7 \pm 0.1$ \\
\hline 2.5 & 12 & 90 & $50.3 \pm 0.1$ \\
\hline 1.25 & 11 & 287 & $102.5 \pm 0.4$ \\
\hline 0.625 & 13 & 382 & $219.9 \pm 1.3$ \\
\hline 0.3125 & 10 & 3667 & $1706 \pm 145$ \\
\hline
\end{tabular}

Analyzing the data presented in Table 1, one can conclude, that despite the large differences in the values of mean $M L T$ and $T_{t}$ values, regardless of the concentration used, the first lethal effects occurred in no more than 13 minutes in each tested group.

\section{Dynamics of toxic effects in Daphnia magna caused by copper ions}

The range of copper sulfate concentrations tested was $0.00625-0.1 \mathrm{mg} / \mathrm{dm}^{3}$. The choice of the concentration range was based on preliminary crustacean toxicity studies, where it was shown that copper ions produce an acute effect at very low doses.

By using the semi-logarithmic plot data (dependence of the probability $(P)$ of the lethal effect on Figure 3 and the logarithm of survival (ln $Q$ ) from time - Figure 4), it can be presumed that copper in organisms produces one lethal toxic effect after exceeding a certain threshold concentration in the biosystem. Type of the achieved curves indicates similar effect for each concentration used, but it develops when a toxicant exceed some threshold concentration in biosystem - the lower the concentration, because the more time it takes for the toxicant to cause the effect.

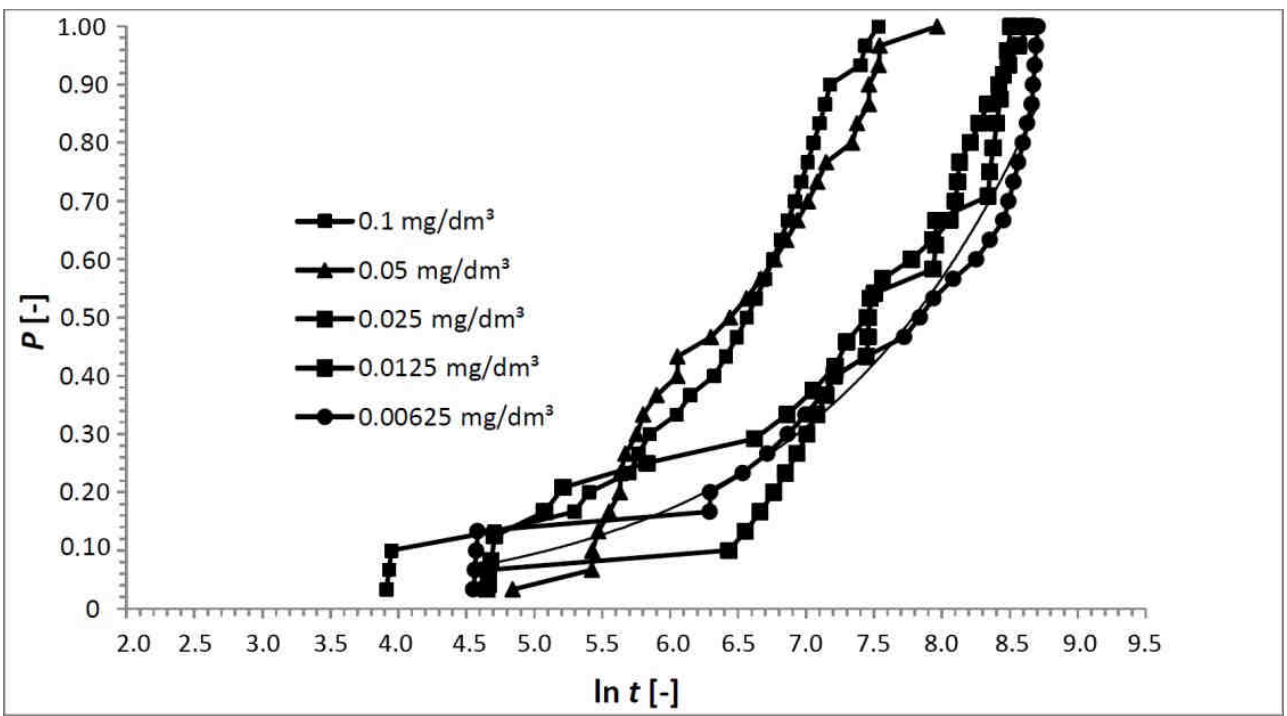

Fig. 3. The dependence of the probability of the lethal effect $(P)$ in Daphnia magna by exposure to copper ions on the logarithm of time 


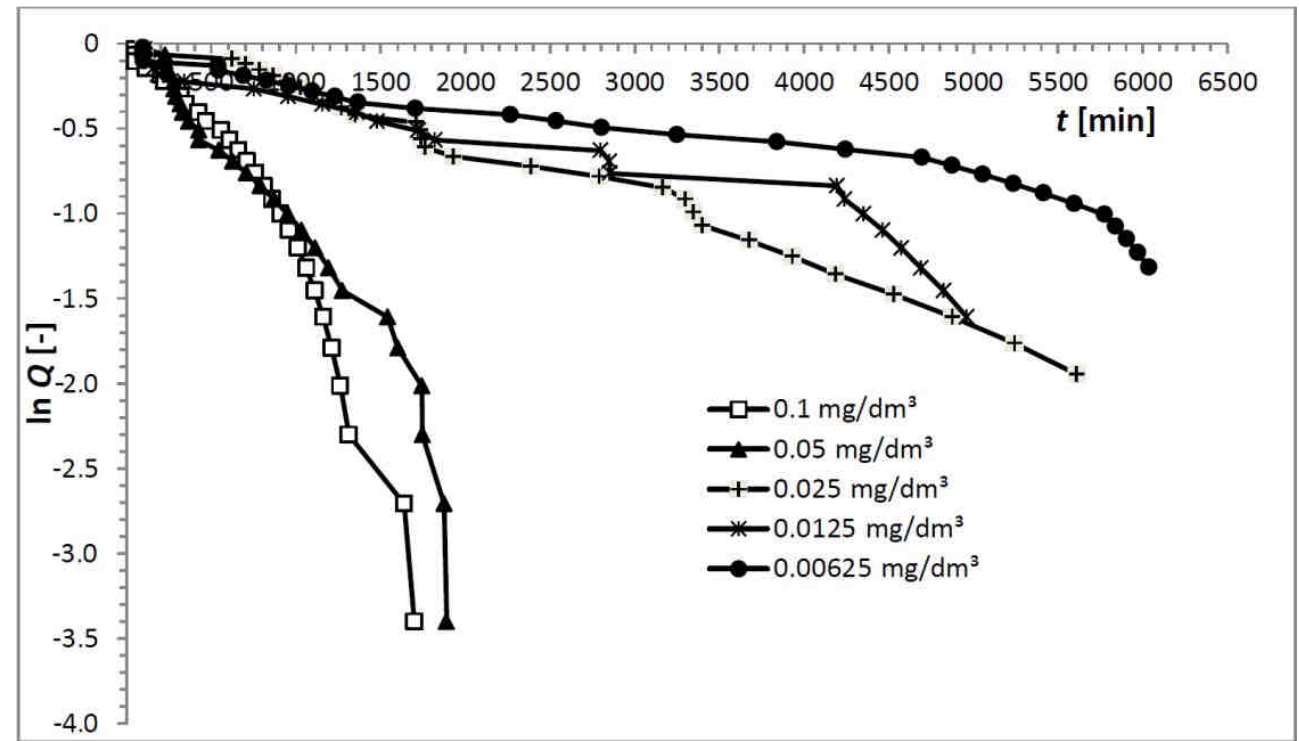

Fig. 4. Survival rate (ln $Q$ ) of Daphnia magna during time exposure to copper ions

Curves shown on Figure 4 suggest presence of two different effects taking place: one for higher concentrations $\left(0.1\right.$ and $\left.0.05 \mathrm{mg} / \mathrm{dm}^{3}\right)$ and one for lower concentrations $\left(0.025-0.00625 \mathrm{mg} / \mathrm{dm}^{3}\right)$, however, computer stimulation showed that for the whole range of concentrations the value of exponential function $(n)$ is 0.58 . The positioning of the data in Figure 4 seems to confirm that we are dealing here with a toxic effect of equal strength, depending only on time, until the toxicant reaches the appropriate concentration in the biosystem of the studied organisms. Curves, as the time of exposure goes by, do not become more steep or concave, only the angle of their inclination changes to both axis. The basic parameters of the dynamics of the lethal effect are presented in Table 2.

Parameters of the dynamics of the toxic effect for Daphnia magna in the presence of various concentrations of copper ions

\begin{tabular}{|c|c|c|c|}
\hline $\boldsymbol{C}\left[\mathbf{m g} / \mathbf{d m}^{3}\right]$ & $\boldsymbol{T}_{\text {in }}[\mathbf{m i n}]$ & $\boldsymbol{T}_{\boldsymbol{t}}$ [min] & $\boldsymbol{M L T}[\mathbf{m i n}]$ \\
\hline 0.1 & 50 & 1868 & $757 \pm 93$ \\
\hline 0.05 & 127 & 2880 & $872 \pm 125$ \\
\hline 0.025 & 105 & 5611 & $2313 \pm 289$ \\
\hline 0.0125 & 106 & 4960 & $2294 \pm 372$ \\
\hline 0.00625 & 95 & 6035 & $3053 \pm 408$ \\
\hline
\end{tabular}

In the acute effect of copper ions on Daphnia magna in all concentrations almost the same value of $T_{i n}$ has been noted. Values of $T_{t}$ decline correspondingly to lower concentration of the toxicant. These data may indicate effective mechanisms for the elimination or metabolization of the toxicant in the test subjects. 


\section{Dynamics of toxic effects in Cypris pubera caused by ammonium ions}

In case of Cypris pubera species concentrations from 0.3125 to $5 \mathrm{~g} / \mathrm{dm}^{3}$ of ammonium ions were used. The exposure time for the lowest, used concentration lasted less than 230 hours. $T_{i n}$ values were in a range of 5 to 20 minutes. In Figures 4 and 5, the relationship between the time and the logarithm of the probability of occurrence of a lethal effect and the logarithm of survival of individuals for the used concentrations of ammonium ions are presented.

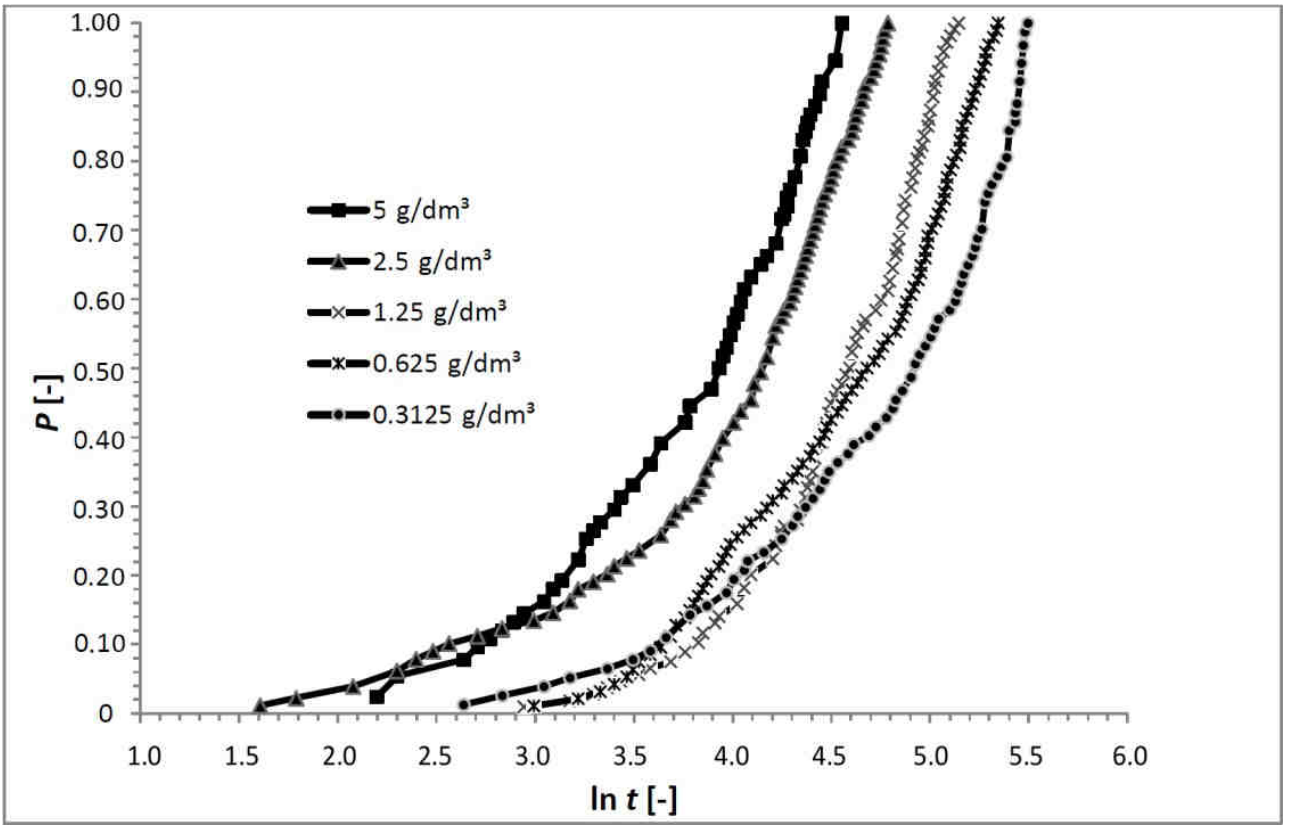

Fig. 5. The dependence of the probability of toxic effect $(P)$ on the time logarithm of time $(\ln t)$ for Cypris pubera organisms at various concentrations of ammonium ions

The characteristics of the obtained curves indicates that the lethal effect is almost uniform in time from the first to the last organism, whereas the difference in the angle of inclination of the curves for the concentrations used results from the proportionately longer intervals between deaths of individuals. All curves have a similar character, along with a decrease in concentration, they move to the right of the ordinate (the slope accounts are the same). A characteristic feature of this process is to extend the time of the initial effect together with a decrease in concentration. This suggests the existence of one toxic mechanism, the development of which is stretched in the long-term with the decrease of the toxicant concentration in the environment. The slope of the curves at all concentrations (Fig. 6) indicates only one mechanism after achieving critical concentration of toxicant in biosystem. Toxicodynamic parameters of ammonium ions (Table 3) show that despite reliable differences, both, for the average survival time $(M L T)$ and terminal times $\left(T_{t}\right)$ for Cypris pubera organisms in different concentrations of ammonium, there are slight differences in the values of initial times of lethal effect development (Table 3). 


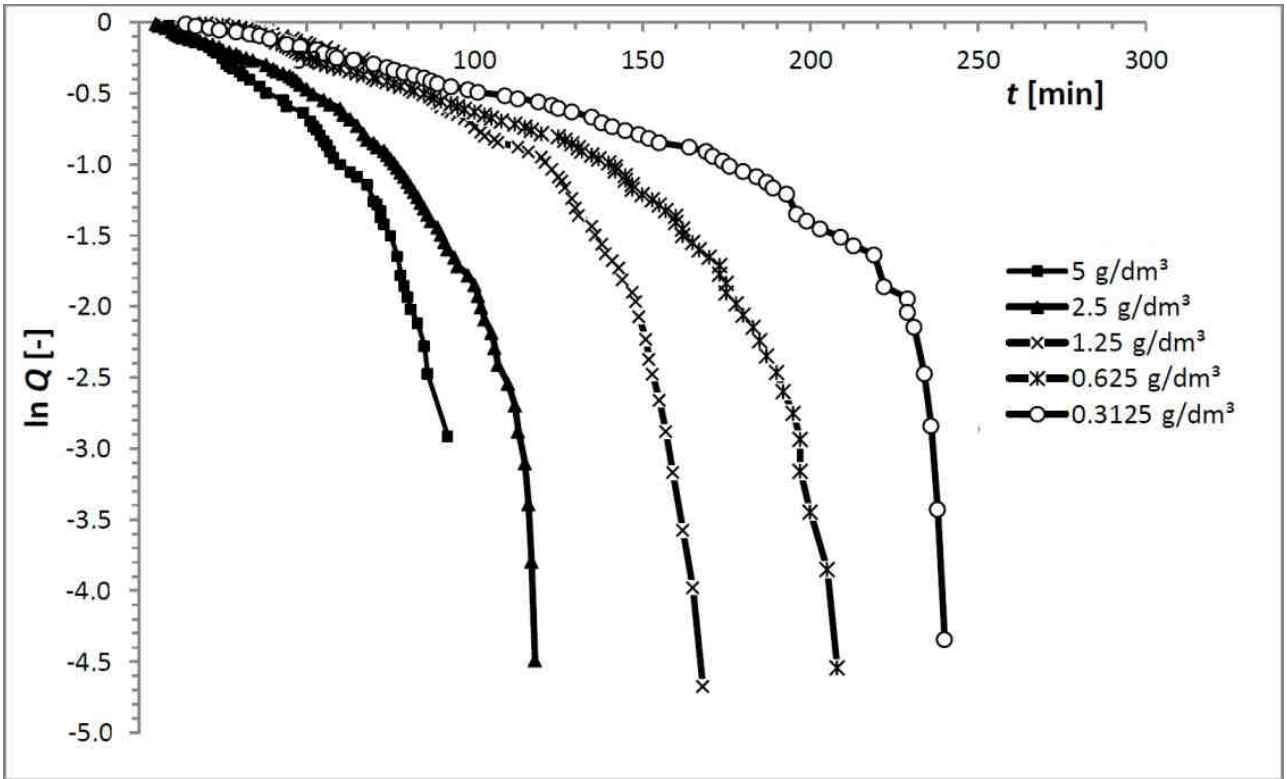

Fig. 6. Dependence of logarithm of survival probability on time for Cypris pubera organisms at various concentrations of ammonium ions

Table 3

Basic parameters of the time of toxic effect for Cypris pubera in the presence of various concentrations of ammonium ions

\begin{tabular}{|c|c|c|c|}
\hline $\boldsymbol{C}\left[\mathbf{g} / \mathbf{d m}^{\mathbf{3}}\right]$ & $\boldsymbol{T}_{\text {in }}[\mathbf{m i n}]$ & $\boldsymbol{T}_{t}[\mathbf{m i n}]$ & $\boldsymbol{M L T}[\mathbf{m i n}]$ \\
\hline 5 & 9 & 95 & $50.5 \pm 4.1$ \\
\hline 2.5 & 5 & 120 & $62.5 \pm 5.5$ \\
\hline 1.25 & 19 & 172 & $100 \pm 12$ \\
\hline 0.625 & 20 & 210 & $111.4 \pm 8.9$ \\
\hline 0.3125 & 14 & 244 & $136 \pm 17$ \\
\hline
\end{tabular}

\section{Dynamics of toxic effects in Daphnia magna caused by copper ions}

The assessment of the toxic effect of copper ions in Cypris pubera in the same concentration range as for Daphnia magna (Figs. 7 and 8) showed other dependencies over time. The relationship between the probability of the effect and the logarithm of time (Fig. 7) shows the curves, which to a large extent, maintain similar shapes with the simultaneous shift in relation to the axis $(P)$ according to the decrease in concentrations.

The dynamics of copper ion toxicity show (Fig. 8) that for concentrations from 0.1 to $0.025 \mathrm{mg} / \mathrm{dm}^{3}$ the lethal effect occurs rapidly after reaching a certain time of exposure. Lower concentrations lead to an effect without acceleration and deceleration. The computer simulation of the time-effect curve showed the presence of two effects: for higher concentrations with exponent value $n=0.75$, and for lower concentrations with exponent value $n=0.2$. 


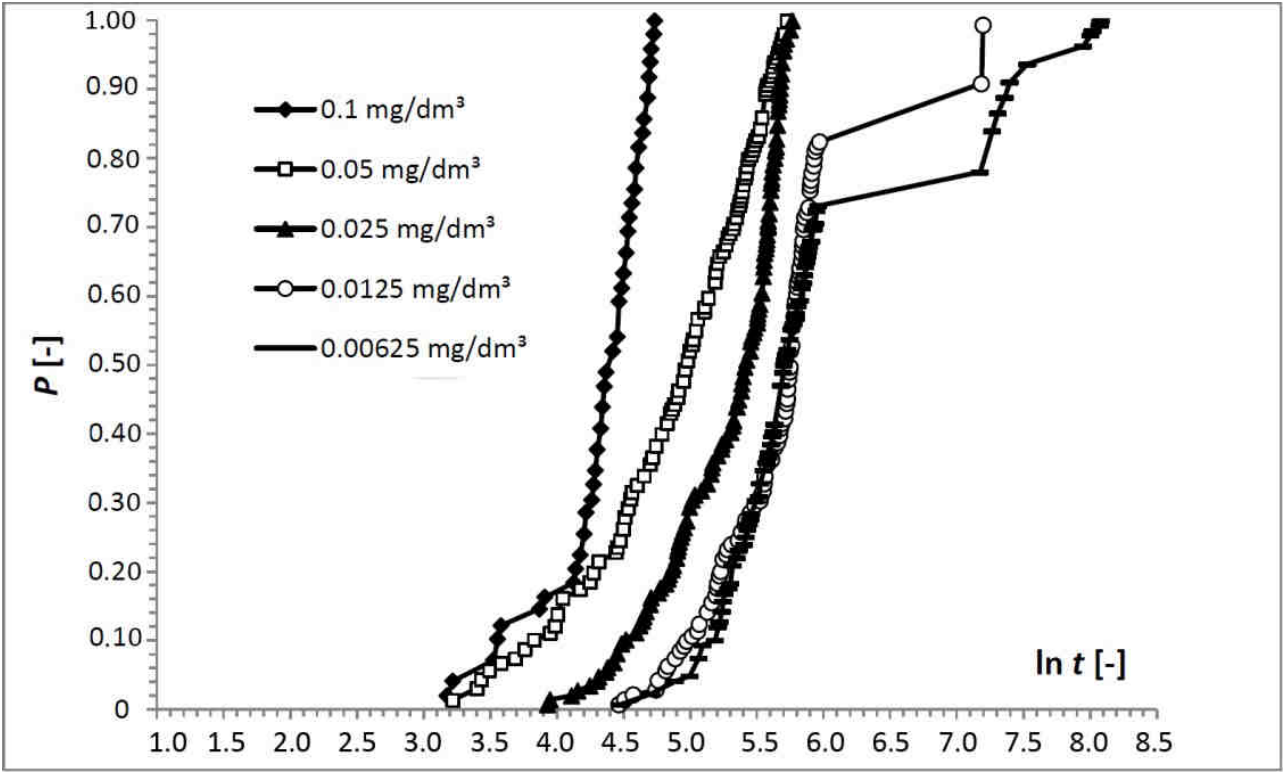

Fig. 7. Dependence of the probability, $P$, of toxic effect caused by copper ions on Cypris pubera on the logarithm of time in various concentrations of this toxicant

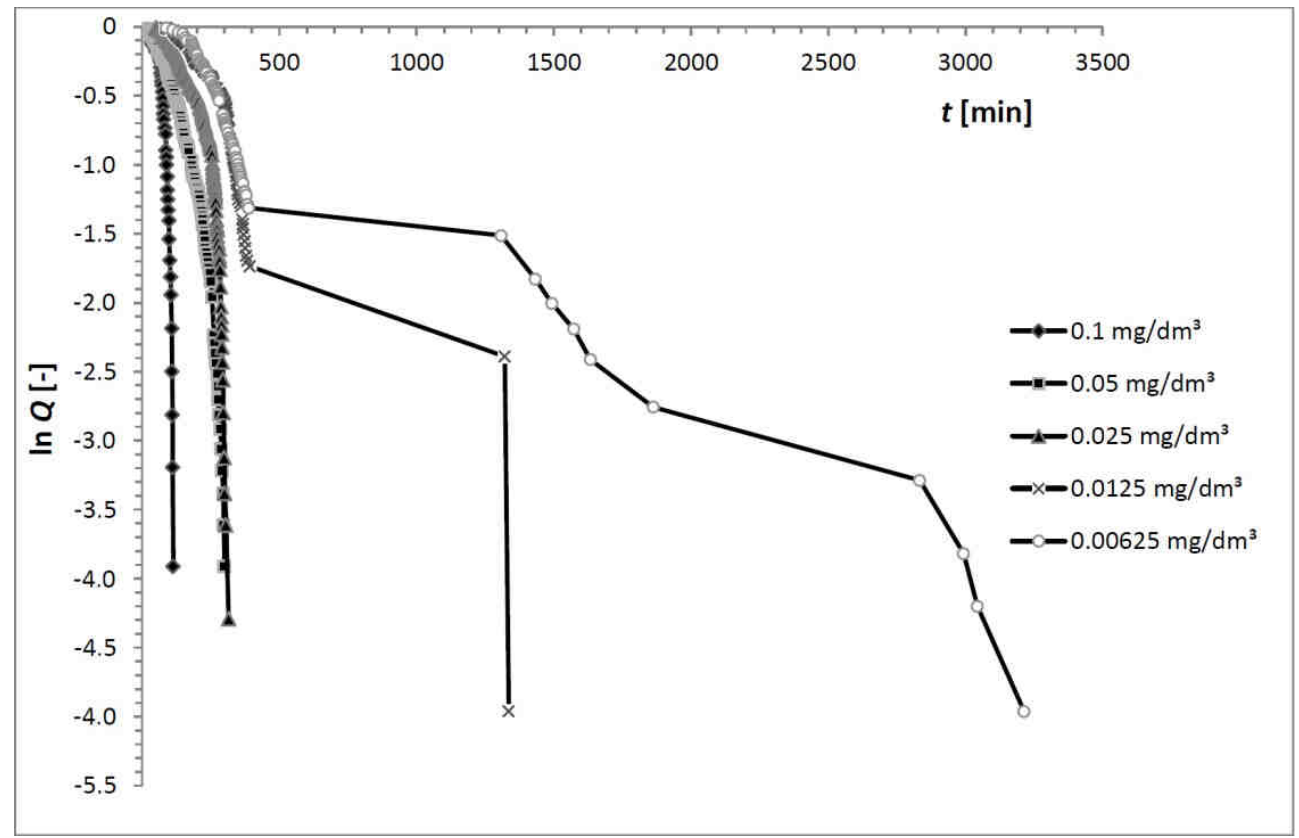

Fig. 8. Survival rate (ln $Q$ ) of Cypris pubera under the exposure to different concentration of copper ions 
The calculated parameters of the effect (Table 4) also show the difference between the test species of crustaceans. The lethal effect among Cypris pubera individuals at these concentrations of copper ions occurs in a much shorter time than in Daphnia magna. However, the beginning time of toxic effects are very similar.

Table 4

Basic parameters of the time of toxic effect for Cypris pubera in the presence of various concentrations of copper ions

\begin{tabular}{|c|c|c|c|}
\hline $\boldsymbol{C}\left[\mathbf{m g} / \mathbf{d m}^{\mathbf{3}}\right]$ & $\boldsymbol{T}_{\text {in }}$ [min] & $\boldsymbol{T}_{\boldsymbol{t}}[\mathbf{m i n}]$ & $\boldsymbol{M L T}[\mathbf{m i n}]$ \\
\hline 0.1 & 24 & 114 & $82.1 \pm 3.9$ \\
\hline 0.05 & 25 & 307 & $153 \pm 9$ \\
\hline 0.025 & 51 & 320 & $208.2 \pm 7.5$ \\
\hline 0.0125 & 87 & 1336 & $453 \pm 24$ \\
\hline 0.00625 & 88 & 3233 & $669 \pm 92$ \\
\hline
\end{tabular}

The use of previously developed models, including the molecular model [15] allows us to obtain information on alternative changes in biosystem properties due to the irreversible interaction of toxicant molecules (L) with macromolecules (R) of the organism what gives a formation of their complexes (RL). Regression methods of calculating based on the molecular model [15-17] allowed to estimate the threshold concentration $\left(C_{t h}\right)$, below which there is no toxic effect, "intrinsic toxicity" $(\alpha)$ of complex "receptor-ligand" RL, apparent constants of decay of receptor-ligand complexes RL $\left(K_{a p p}\right)$ ). Calculated parameters are presented in Table 5.

Table 5

Parameters of acute ammonium and copper ions comparison toxicity for all tested species

\begin{tabular}{|c|c|c|}
\hline \multirow{2}{*}{ Parametr } & Amonnium ions & Copper ions \\
\cline { 2 - 3 } & \multicolumn{2}{|c|}{ Daphnia magna } \\
\hline$C_{t h}\left[\mathrm{mg} / \mathrm{dm}^{3}\right]$ & 0.14 & 0.009 \\
\hline$\alpha$ & 71.17 & 423.04 \\
\hline$K_{a p p}$ & 10.00 & 3.9 \\
\hline$C_{t h}\left[\mathrm{mg} / \mathrm{dm}^{3}\right]$ & \multicolumn{2}{|c|}{ Cypris pubera } \\
\hline$\alpha$ & 9.067 & 0.007 \\
\hline$K_{a p p}$ & 61.72 & 25.37 \\
\hline
\end{tabular}

Calculation of research data according to the mathematical apparatus with molecular models allows us to compare the process of the acute effect between studied species, and the "strength" of the interaction of different toxicants among each species separately.

\section{Discussion}

The toxic effect is manifested only when the toxicant concentration reaches a certain threshold value in specific sites of biosystem. The achievement of this concentration is strictly dependent on the time of exposure to the toxicant, but also on the metabolic processes with which the organism attempts to defend itself from the toxic effects, i.e. slowdown of absorption, acceleration of excretion, metabolization, deposition in tissues of lesser importance for survival $[18,19]$. Wider, than based only on $L C_{50}$ (median, lethal concentration) of individuals values, insight into the toxicity of the tested compound is 
given by studies in which time plays important role as the toxicant concentration [20, 21]. It should be emphasized that the assumption of used models [15-17] is that concentration of toxicant in biosystem is directly proportional to its concentration in the environment. This is possible only under conditions of irreversible, acute effect. This assumptions were important while choosing a concentration range that give an $100 \%$ lethal effect in studied groups. This approach minimize the possibility of sub-acute and sub-chronic effects [22]. Possibility of observing the development of the lethal effect allows to characterize different mechanisms of action of ammonium ions on the studied organisms. In daphnia and ostracods the rate with which the lethal effects of the toxicant occurred along with increased concentration of the toxicant has been also higher, but the dynamics of these effects varied. Concentrations - balance of the process after reaching a specified concentration in the biofase is directed towards irreversible changes. The dynamics of the lethal effect of ammonium ions in Cypris pubera is proportional to the concentration used. By comparing the values of $C_{t h}$ we can conclude that this species is more sensitive to low concentrations of ammonium than Daphnia magna. A large difference in the "intrinsic toxicity" $(\alpha)$ of receptor-ligand complexes between species suggests the influence of sub-acute effects on the overall dynamics of Cypris pibera mortality. A common feature of the action of ammonium ions on the tested hydrobiones is the short initial time of the effect, which may be related to the general mechanism of interaction of $\mathrm{NH}_{4}{ }^{+}$ions in aquatic organisms which compete with $\mathrm{K}^{+}$ions during membrane transport (both ions have the same ionic radius) and as a result change in the polarization of membranes and the induction of $\mathrm{pH}$ changes within the cytoplasm of respiratory tissue cells [23].

When comparing the dynamics of interaction of copper ions on tested species, it can be noticed that, unlike ammonium ions, very low concentrations cause a rapid (lethal) effect, and $C_{t h}$ is almost identical and is within the range of $0.007-0.009 \mathrm{mg} / \mathrm{dm}^{3}$.

\section{Conclusions}

The proposed dynamic model of an alternative effect (all or nothing), combined with regression analysis of research data, is useful to describe the functional dynamics of xenobiotics as well as the basic parameters $\left(T_{t}, T_{i n}, M L T, C_{t h}, K_{a p p}\right)$ in the absence of information about the exact mechanisms of the toxicant's interaction with the "biophase" of organism. Such information give some advantage in understanding and predicting the toxic effects and might be used instead of other, controversial values such as NOEC or LOEC [24] or can help to develop models used in toxicology [25-27] by including time as an equally important determinant of a toxic effect.

The Cypris pubera species is more sensitive to the effects of copper ions than Daphnia magna, as evidenced by the average survival time (shorter by several times) and twenty times smaller $K_{a p p}$ value of toxicant-macromolecules complex.

\section{References}

[1] Walker CH, Sibly RM, Hopkin SP, Peakall DB. Principles of Ecotoxicology. 4th Ed. Boca Raton: CRC Press; 2012. ISBN: 9781439862667 - CAT\# K12907.

[2] Bosch AC, O'Neill B, Sigge GO, Kerwath SE, Hoffman LC. Heavy metals in marine fish meat and consumer health: a review. J Sci Food Agric. 2016;96(1):32-48. DOI: 10.1002/jsfa.7360.

[3] Adams WJ, Blust R, Borgmann U, Brix KV, DeForest DK, Green AS, et al. Utility of tissue residues for predicting effects of metals on aquatic organisms. Integr Environ Assess Manage. Special Issue: Tissue Residue Approach Special Series. 2011;7(1):75-98. DOI: 10.1002/ieam.108. 
[4] Cheng S. Heavy metal pollution in China: origin, pattern and control. Environ Sci Pollut Res. 2003;3:192-198. DOI: 10.1065/espr2002.11.141.1.

[5] Atli G, Canli M. Alterations in ion levels of freshwater fish Oreochromis niloticus following acute and chronic exposures to five heavy metals. Turk J Zool. 2010;35:725-736. DOI: 10.3906/zoo-1001-31.

[6] Atli G, Canli M. Essential metal ( $\mathrm{Cu}, \mathrm{Zn})$ exposures alter the activity of ATPases in gill, kidney and muscle of Tilapia Oreochromis niloticus. Ecotoxicology. 2011; 20(8):1861-1869. DOI: 10.1007/s10646-011-0724-z.

[7] Basha PS, Rani AU. Cadmium-induced antioxidant defense mechanism in freshwater teleost Oreochromis mossambicus (Tilapia). Ecotox Environ Safety. 2003;56:218-221. DOI: 10.1016/S0147-6513(03)00028-9.

[8] Philips S, Laanbroek HJ, Verstraete W. Origin, causes and effects of increased nitrite concentrations in aquatic environments. Rev Environ Sci Bio/Technol. 2002;1(2):115-141. DOI: 10.1023/A:1020892826575.

[9] Hoffman DJ, Rattner BA, Burton GA Jr, Cairns J Jr. Handbook of Ecotoxicology. 2nd Ed. Boca Raton: CRC Press; 2003. ISBN: 9781566705462 - CAT\# L1546.

[10] Traudt EM, Ranville JF, Smith SA, Meyer JS. A test of the additivity of acute toxicity of binary-metal mixtures of $\mathrm{Ni}$ with $\mathrm{Cd}, \mathrm{Cu}$, and $\mathrm{Zn}$ to Daphnia magna, using the inflection point of the concentration response curves. Environ Toxicol Chem. 2016;35:1843-1851. DOI: 10.1002/etc.3342.

[11] Cui R, Kwak JI, An YJ. Comparative study of the sensitivity of Daphnia galeata and Daphnia magna to heavy metals. Ecotox Environ Safety. 2018;162:63-70. DOI: 10.1016/j.ecoenv.2018.06.054.

[12] Santore RC, Di Toro DM, Paquin PR, Allen HE, Meyer JS. Biotic ligand model of the acute toxicity of metals. 2. Application to acute copper toxicity in freshwater fish and Daphnia. Environ Toxicol Chem. 2001;20:2397-2402. DOI: 10.1002/etc.5620201035.

[13] Wang N, Ingersoll CG, Hardesty DK, Ivey CD, Kunz JL, May TW, et al. Acute toxicity of copper, ammonia, and chlorine to glochidia and juveniles of freshwater mussels (Unionidae). Environ Toxicol Chem. 2007;26(10):2036-2047. DOI: 10.1016/j.aquatox.2008.04.003.

[14] OECD Test Guidelines for the Chemicals. https://www.oecd.org/env/ehs/testing/ oecdguidelinesforthetestingofchemicals.htm.

[15] Zinkovsky VG, Zhuk OV, Oloś G, Zhuk M. Dynamic modelling of xenobiotic action on organism using parameters of lethal toxic effect. Proc XVI National Conf Applications Mathematics Biology Medicine. Krynica, Sept 14-16, 2010; 111-116. ISBN: 9788374643344.

[16] Zinkovskyy YG, Zhuk OV, Oloś G, Zhuk M, Jabłecki R. Opracowanie regresyjnych metod obliczania zasadniczych parametrów alternatywnych toksycznych efektów ksenobiotyków. Chem Didact Ecol Metrol. 2011;16(1-2):29-34. https://drive.google.com/file/d/19IXQtn5nEtoz1uLqBgP_Nz2F0Teq5tMQ/view.

[17] Potrohov AS, Zinkovsky OG, Zinkovsky VG, Oloś G. Dynamika efektów toksycznych różnych stężeń jonów amonu u ryb. (Dynamics of toxic effects of different amonium ions concentrations on fish.) Chem Didact Ecol Metrol. 2010;15(1):29-38. https://drive.google.com/file/d/ 18kBfpmL45xcmLrUyY0qu8ycgDu2tnB-A/view.

[18] Henry RP, Lucu Č, Onken H, Weihrauch D. Multiple functions of the crustacean gill: osmotic/ionic regulation, acid-base balance, ammonia excretion, and bioaccumulation of toxic metals. Front Physiol. 2012;3:431. DOI: 10.3389/fphys.2012.00431.

[19] Atli G, Canli M. Enzymatic responses to metal exposures in a freshwater fish Oreochromis niloticus. Comp Biochem Physiol. 2007;145:282-287. DOI: 10.1016/j.cbpc.2006.12.012

[20] Mackay D, Celsie AK, Parnis JM, McCarty LS, Arnot JA, Powell DE. The chemical exposure toxicity space (CETS) model: Displaying exposure time, aqueous and organic concentration, activity, and onset of toxicity. Environ Toxicol Chem. 2017;36(5):1389-1396. DOI: 10.1002/etc.3668.

[21] Kim S, Samanta P, Yoo J, Kim WK, Jung J. Time-dependent toxicity responses in Daphnia magna exposed to $\mathrm{CuO}$ and $\mathrm{ZnO}$ nanoparticles. Bull Environ Contam Toxicol. 2017;98(4):502-507. DOI: 10.1007/s00128-016-2022-1

[22] Murray L, Daly F, Little M, Cadogan M. Toxicology Handbook. Lismore: Elsevier; 2015. ISBN: 9780729579391.

[23] Wang HJ, Xiao XC, Wang HZ, Li Y, Yu Q, Liang XM, et al. Effects of high ammonia concentrations on three cyprinid fish: Acute and whole-ecosystem chronic tests. Sci Total Environ. 2017;598:900-909. DOI: 10.1016/j.scitotenv.2017.04.070

[24] Laskowski R. Some good reasons to ban the use of NOEC, LOEC and related concepts in ecotoxicology. Oikos. 1995; 1:140-144. DOI: 10.2307/3545738.

[25] Hamilton MA, Russo RC, Thurston RV. Trimmed Spearman-Karber method for estimating median lethal concentrations in toxicity bioassays. Environ Sci Technol. 1977;11(7):714-719. DOI: 10.1021/es60130a004.

[26] Principles and Methods of Toxicology. 5th Ed. Boca Raton: CRC Press; 2007. DOI: 10.1201/b14258.

[27] De Laender F, De Schamphelaere KA, Vanrolleghem PA, Janssen CR. Comparison of different toxic effect sub-models in ecosystem modelling used for ecological effect assessments and water quality standard setting. Ecotoxicol Environ Safety. 2008;69(1):13-23. DOI: 10.1016/j.ecoenv.2007.08.020. 